\section{Sensitive Two-Color Whole-Mount In Situ Hybridizations Using Digoxygenin- and Dinitrophenol-Labeled RNA Probes}

\section{BioTechniques 32:494-500 (March 2002)}

Two-color whole-mount in situ hybridization is a powerful technique for comparing the spatial expression patterns of two genes in developing em bryos or within a given adult tissue. Many current procedures use two genespecific antisense RNA probes, each incorporating a different chemical moiety that is recognized by a specific antibody. Typically, the first gene-specific RNA probe is labeled with digoxygenin (DIG) and the second with fluorescein or biotin. After hybridization to the embryos, each bound antisense probe is then visualized using a specific enzyme-conjugated antibody and a distinctive color reaction. These procedures work well in situations when both of the target genes are expressed at high levels but are less reliable for cases in which one or both of the genes are expressed at moderate or low levels. Often, these difficulties can be attributed to the differing sensitivities of the two hapten/antibody/color detection systems that are used.

Dinitrophenol (DNP) has been used as an alternative tag for labeling oligonucleotides for in situ hybridizations of tissue sections or for nonradioactive detection of DNA fragments $(1,3,4,7,8)$. We have investigated the use of DNP for labeling antisense RNA probes for use in two-color wholemount in situ hybridizations. Specifically, we have replaced fluorescein-labeled RNA probes with their DNP-labeled counterparts and used an alkaline phosphatase (AP)-conjugated, anti-DNP Fab for immunostaining. In our hands, this hapten/antibody pair generally gives much less background staining, even after long development times, with signals comparable to or stronger than those produced with the corresponding fluorescein detection system. Consequently, using the combination of DIG- and DNP-labeled antisense RNAs, we observe significantly improved reliability in two-color whole-mount in situ hybridizations, especially with probes to mRNAs of low or moderate abundance.

DNP-labeled RNA probes were prepared by transcription in vitro with standard rNTPs and then tagged covalently with DNP by chemical modification using the Label IT $^{\circledR}$ DNP Nucleic Acid Labeling System (Mirus, Madison, WI, USA). The DNP labeling procedure adds the DNP moiety to non-base-pairing sites on the guanine ring. According to the manufacturer's specifications, only one DNP tag is added per 20-60 bp. Therefore, the "specific activity" of the DNP-labeled probe is theoretically less than that of a DIG probe, since a DIG group is reported to be present every 20-25 nucleotides in DIG-labeled transcripts (Roche Molecular Biochem icals, Indianapolis, IN, USA).

To compare the DIG and DNP probes, we used equal concentrations of the corresponding probes for hybridization, identical dilutions of the AP-conjugated anti-DIG or anti-DNP Fab fragments, and the same staining times with BM Purple (Figure 1). Antisense probes to the zebrafish no tail $(n t l)$ gene were compared by in situ hybridization with 4-7 somite-stage zebrafish embryos. The $n t l$ gene was chosen because of its distinctive expression pattern in the notochord and tailbud (12). Surprisingly, the DNP and DIG $n t l$ probes gave essentially the same staining intensity and specificity (Figure 1A). The DIG signal was slightly stronger, but the nonspecific background was also elevated slightly with the DIG probe. The lower specific activity of the DNP probe is presumably compensated by another factor, either increased hybridization efficiency or an antibody-dependent parameter.

To test the suitability of DNP-labeled RNA probes in two-color wholemount in situ hybridizations, the DNPlabeled $n t l$ probe was hybridized jointly with a DIG-labeled spadetail (spt) probe. The spt and ntl expression domains overlap in the tailbud of the zebrafish embryos but not in the notochord, where only $n t l$ is expressed. $(6,12)$. The DNP and DIG probes were visualized using $\mathrm{p}$-iodonitrotetrazolium violet/X-gal 4-toluidine (INT RED/
BCIP; Sigma, St. Louis, MO, USA and Roche Molecular Biochemicals) and BM Purple as the AP substrates, respectively. The INT RED/BCIP staining was done using the method of Sagerström et al. (11), as modified by Liang et al. (9). The $n t l$ and spt expression domains were easily detected with high specificity (Figure 1B). The punctate nature of the $n t l$ staining (red) reflects the expression of $n t l$ within specific notochord cells. This suggests that, using DNP probes, two-color whole-mount in situ hybridizations can provide single-cell resolution. This was confirmed separately by in situ hybridization using a DNP-labeled pitx2 probe and color development with INT RED/BCIP. We were able to see the staining of the individual cells (putative Rohon-Beard neurons; Figure $1 \mathrm{C}$, arrow) where the pitx 2 homeobox gene is expressed (5).

Finally, we compared DNP- and fluorescein-labeled antisense RNA probes. Higher, nonspecific background staining and/or lower signals were seen more often with the fluorescein probes. For example, Figure 1, D-G, illustrates the results from in situ hybridizations with either a fluorescein- or a DNP-labeled lefty2 probe; color development was with INT RED/BCIP. Lefty2 encodes a developmentally regulated growth factor (2). With the fluorescein-labeled probe, most embryos showed high $(47 \%)$ (Figure $1 \mathrm{G})$ or moderate $(47 \%)$ background staining in addition to the specific staining of the heart tube $(n=$ $34)$. Only a few embryos (6\%) were stained with acceptably low levels of background (Figure 1F). In contrast, with the DNP-labeled lefty 2 probe, $97 \%$ of the embryos $(n=32)$ showed little or no background (Figure 1D), and even the embryo with the highest background showed an acceptable signal-to-noise ratio (Figure 1E). Figure 1, $\mathrm{H}$ and $\mathrm{I}$, shows a two-color/two-probe in situ hybridization experiment in which we tested a fluorescein- or DNP-labeled RNA probe in combination with a DIG-labeled RNA probe. We used a DIG-labeled cyclops probe with either the fluorescein- or DNP-labeled lefty 2 probe. At the 19-23 somite stages, cyclops shows moderately strong expression in the brain and weak expression in the left lateral plate mesoderm, while lefty 2 shows moderately strong expression on the left 
side $(2,10)$. DIG-probe hybridization was visualized by staining with BM Purple, and INT RED/BCIP was used to reveal the hybridized fluorescein or DNP probe. Staining of the embryos was stopped as soon as the region of overlapping lefty2/cyclops signals or the nonspecific background became evident-whichever came first. This com parison showed clearly that the DIG/ DNP probe combination was better than the DIG/fluorescein probe combination in detecting the overlapping and the unique zones of cyclops and lefty 2 mRNA expression (Figure 1, H and I).

In summary, the combination of DIG- and DNP-labeled antisense RNA probes is an effective alternative to standard approaches for the two-color whole-mount in situ hybridization analysis of gene expression. At least under some circumstances, the DIG/ DNP system may be the best choice in terms of its ability to minimize background problems without compromising signal strength.

Each DIG-labeled antisense RNA probe was synthesized by in vitro transcription using the DIG RNA Labeling Kit (SP6/T7; Roche Molecular Biochemicals), according to the manufacturer's instructions. After a DNase treatment, unincorporated nucleotides were removed by chromatography through two successive G50 RNA Quick Spin ${ }^{\mathrm{TM}}$ Columns (Roche Molecular Biochemicals) (1100× $g$ for 2 $\mathrm{min})$. An aliquot was taken for gel analysis, and the remainder was precipitated with ethanol. RNA synthesis was

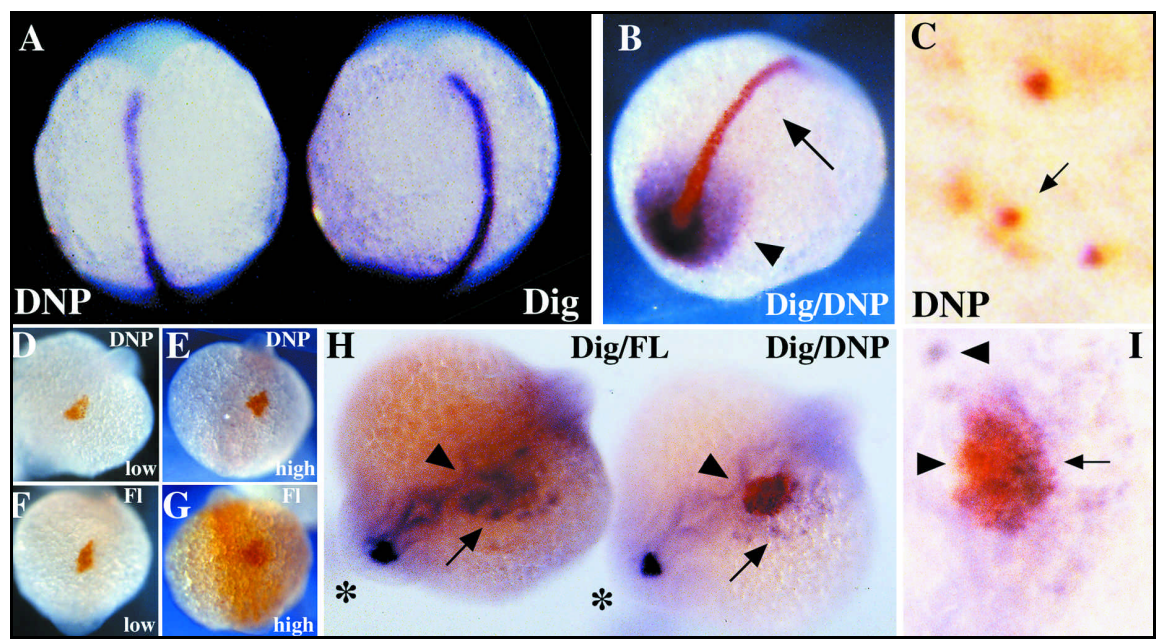

Figure 1. Whole-mount in situ hybridizations in zebrafish comparing DNP antisense RNA probes to DIG- or fluorescein-labeled antisense RNA probes. (A) Somite-stage embryos (4-7) hybridized with DNP or DIG $n t l$ probes $(25 \mathrm{ng} / \mathrm{mL}$ probe concentration; 1:2000 anti-DNP-AP-Fab dilution; and 1:2000 anti-DIG-AP-Fab dilution). The BM Purple staining reaction was done for $3 \mathrm{~h}$ at room temperature. Dorsal views showing notochord staining. (B) Two-color in situ hybridization with a DNP ntl probe $(62.5$ $\mathrm{ng} / \mathrm{mL}$ probe; 1:5000 dilution of anti-DNP-AP-Fab; and INT RED/BCIP staining) plus a DIG spt probe ( $25 \mathrm{ng} / \mathrm{mL}$ probe; 1:2000 dilution of anti-DIG-AP-Fab; and BM purple staining) on 4-7 somite-stage em bryos. Dorsal posterior view. The arrow points to red staining in the notochord, which is indicative of $n t l$ gene expression. The arrowhead points to purple staining in the tailbud, which is indicative of spt gene expression. (C) Closeup dorsal view of 22 somite-stage embryo hybridized with a DNP-pitx 2 probe (1:1000 anti-DNP-AP-Fab; INT RED/BCIP). Arrow, staining in a single cell. (D-G) Dorsal-anterior views of 22-24 somite-stage embryos hybridized with DNP lefty2 (D and E) or fluorescein lefty2 (F and G) probes that show specific staining of the heart tube $(200 \mathrm{ng} / \mathrm{mL}$ DNP or fluorescein probe; 1:2000 dilution antiDNP-AP-Fab; and 1:5000 dilution of anti-fluorescein-AP-Fab). INT RED/BCIP staining reaction was done for $12 \mathrm{~h}$ at room temperature. Low, representative embryo with low nonspecific background staining. High, representative embryo with high nonspecific background staining. $(\mathrm{H})$ Dorsal-anterior views of 19-23 somite-stage embryos hybridized with a combination of a DIG cyclops plus a fluorescein lefty2 probe (left, $0.42 \mu \mathrm{g} / \mathrm{mL}$ fluorescein probe) or plus a DNP lefty 2 probe (right, $1 \mu \mathrm{g} / \mathrm{mL}$ DNP probe). Hybridized cyclops probe was detected with a 1:2000 dilution of anti-DIG-AP-Fab and BM purple; lefty2 probe with a 1:2000 dilution of anti-fluorescein-AP-Fab or a 1:500 dilution of anti-DNP-AP-Fab and INT RED/BCIP. Arrows (left lateral plate mesoderm) and asterisks (left dorsal diencephalon) point to areas of cyclops expression that do not overlap lefty2. Arrowhead, zone of overlap of cyclops and lefty 2 in the heart field. (I) Higher magnification view of the zone of overlap from the DIG/DNP in situ hybridization (em bryo on the right in panel $\mathrm{H}$ ). Arrowheads, regions of purple or red stain where only cyclops or lefty 2 is expressed. Arrow, region of brown stain where cyclops and lefty 2 overlap in the heart field.

quantitated by running the aliquot out on a $1.2 \%$ agarose-TBE gel using RNA mass standards and visualizing the bands by ethidium bromide staining. After ethanol precipitation, the probe stock was resuspended in RNase-free water or in $25 \%$ formamide, $2.5 \times \mathrm{SSC}$, $2.5 \mathrm{mM}$ EDTA, $0.05 \%$ Tween $^{\circledR} 20$, $0.05 \%$ CHAPS, and stored at $-80^{\circ} \mathrm{C}$ or $-20^{\circ} \mathrm{C}$, respectively, until use.

Fluorescein-labeled RNAs were prepared using a fluorescein-12-UTP RNA labeling mixture (Roche Molecular Biochemicals), following the manufacturer's instructions, and purified, quantitated, and stored as described earlier.

Each DNP-labeled antisense RNA probe was prepared by covalent modification of an unlabeled transcript. The unlabeled antisense RNA was made by transcription in vitro with the DIG RNA Labeling Kit using an unlabeled rNTP mixture $(1 \mathrm{mM}$ final concentration of each rNTP) in place of the standard DIG-UTP mixture. After DNase treatment, the unincorporated nucleotides were removed by centrifuging the reaction through two successive G50 RNA Quick Spin Columns $(1100 \times g$ for 2 min), followed by an ethanol precipitation. The RNA yield was estimated using the same method as described earlier for DIG- and fluorescein-RNA probes. The unlabeled RNA was resuspended in water at $200 \mathrm{ng} / \mu \mathrm{L}$ and was then linked to DNP groups using the $L a$ bel IT DNP Nucleic Acid Labeling Kit, according to the manufacturer's protocol. We found that a 2-fold deviation up or down from the recommended ratio of RNA to DNP reagent $(2 \mu \mathrm{g}$ RNA/4 $\mu \mathrm{L}$ reconstituted Label IT reagent) did not significantly affect probe sensitivity. The unincorporated DNP labeling reagent was removed by centrifuging the labeling reactions through two successive G50 RNA Quick Spin Columns (1100× $g$ for $2 \mathrm{~min})$. After ethanol precipitation, the DNP-labeled RNA was resuspended in water and stored at $-80^{\circ} \mathrm{C}$ until use.

Working stocks of anti-DIG APconjugated Fab (Roche Molecular Biochemicals), anti-DNP AP-Fab [AP-Fab from HybQUEST ${ }^{\mathrm{TM}}$ Complete (DNP) System; Mirus], and anti-fluorescein AP-Fab (Roche Molecular Biochemicals) were prepared by pre-adsorbing a 1:100 dilution of each antibody in Blocking Solution A against fixed ze- 
brafish embryos. Pre-adsorption was done overnight at $4^{\circ} \mathrm{C}$ with mild shaking. Blocking Solution A consisted of $2 \%$ blocking reagent (Roche Molecular Biochemicals) plus 5\% heat-inactivated lamb serum in $1 \times$ maleic acid buffer (MAB; $0.1 \mathrm{M}$ maleic acid, pH 7.5, 150 $\mathrm{mM} \mathrm{NaCl}$ ).

Approximately 40 embryos were used per in situ hybridization. The em bryos were fixed in $4 \%$ paraformaldehyde and stored in $100 \%$ methanol until use. Rehydration of embryos, hybridization with a single labeled antisense RNA probe, and post-hybridization washing were done according to a standard zebrafish whole-mount in situ protocol (13). Briefly, embryos were rehydrated by washes in $50 \% \mathrm{MeOH} / 50 \% \mathrm{PBTw}$, $30 \% \mathrm{MeOH} / 70 \%$ PBTw, $100 \%$ (i.e., $1 \times$ ) PBTw (1× PBS, $0.2 \%$ BSA, $0.1 \%$ Tween 20). Embryos were permeabilized by incubation in cold $\left(-20^{\circ} \mathrm{C}\right)$ ace- tone for $8 \mathrm{~min}$, followed by two washes in $1 \times$ PBTw. Embryos older than $24 \mathrm{~h}$ were treated with proteinase $\mathrm{K}$ before the acetone step ( $4 \mathrm{~min}$ in $10 \mu \mathrm{g} / \mathrm{mL}$ proteinase $\mathrm{K}$ in $1 \times \mathrm{PBTw}$ at $25^{\circ} \mathrm{C}$ ). Em bryos were prehybridized in $1 \times$ hybridization buffer $(50 \%$ formamide, $5 \times$ SSC, 5 mM EDTA, $0.1 \%$ Tween 20, $0.1 \%$ CHAPS, $80 \mathrm{ng} / \mathrm{mL}$ heparin, 1 $\mathrm{mg} / \mathrm{mL}$ torula RNA) at $65^{\circ} \mathrm{C}$ for $3 \mathrm{~h}$. Probe(s) were added to the $1 \times$ hybridization buffer to a final concentration of $0.025-1 \mu \mathrm{g} / \mathrm{mL}$, depending on the target mRNA abundance. The Figure 1 legend details the specific probe concentrations for the individual experiments. The resulting probe solution was heated to $80^{\circ} \mathrm{C}$ for $2 \mathrm{~min}$ and quenched on ice. At the end of the prehybridization period, the prehybridization solution was removed, the quenched probe solution was added, and the embryos and probe were hybridized together at $65^{\circ} \mathrm{C}$ overnight.
The embryos were then washed successively as follows: twice in wash solution 1 for $30 \mathrm{~min}$ at $65^{\circ} \mathrm{C}$; twice in wash solution 2 for $15 \mathrm{~min}$ at $65^{\circ} \mathrm{C}$; twice in wash solution 3 for $30 \mathrm{~min}$ at $65^{\circ} \mathrm{C}$; and once in $1 \times \mathrm{MAB}$ for $15 \mathrm{~min}$ at room temperature (approximately $25^{\circ} \mathrm{C}$ ). Wash solution 1 consisted of $50 \%$ formamide, $2 \times$ SSC, $0.3 \%$ CHAPS, wash solution 2 consisted of $2 \times \mathrm{SSC}, 0.3 \%$ CHAPS, and wash solution 3 consisted of $0.2 \times \mathrm{SSC}, 0.3 \%$ CHAPS.

After the last post-hybridization wash, the embryos were blocked with Blocking Solution A (for BM Purple staining) or Blocking Solution B (for INT RED/BCIP staining) for $1 \mathrm{~h}$ at room temperature (Blocking Solution A, $2 \%$ blocking reagent plus $5 \%$ heatinactivated lamb serum in $1 \times$ MAB; Blocking Solution B, 20\% heat-inactivated lamb serum, $2 \%$ blocking reagent, $5 \%$ heat-inactivated goat serum in $1 \times$ 
MAB). Pre-adsorbed anti-DIG, antiDNP, or anti-fluorescein AP-conjugated Fab antibodies were added at a 1:500-1:5000 dilution in blocking solution and incubated for 3-4 $\mathrm{h}$ at room temperature or overnight at $4^{\circ} \mathrm{C}$ with mild shaking. Antibody was removed by multiple washes with $1 \times$ PBTw or MABTw $(1 \times$ MAB $+0.1 \%$ Tween 20$)$ with mild shaking, followed by two (DIG/DNP in situ hybridizations) or three rinses (fluorescein in situ hybridizations) with $1 \times$ staining buffer (0.1 M Tris-HCl, $\mathrm{pH}$ 9.5, 0.1 M NaCl, $50 \mathrm{mM} \mathrm{MgCl}_{2}, 0.1 \%$ Tween $20,5 \mathrm{mM}$ Levamisol) for $5 \mathrm{~min} /$ rinse at room tem perature. The embryos were then stained with BM Purple, according to manufacturer's directions, or with INT RED/BCIP, according to Liang et al. (9). The embryos were stained in the dark at room temperature in INT developer ( $1 \times$ staining buffer, $10 \%$ polyvinyl alcohol, $200 \mu \mathrm{g} / \mathrm{mL}$ INT, $175 \mu \mathrm{g} / \mathrm{mL}$ $\mathrm{BCIP})$ until the color developed. A concentrated INT stock can be made up at $55 \mathrm{mg} / \mathrm{mL}$ in dimethylformamide. The stock is good for several weeks if it is stored in the dark at $-20^{\circ} \mathrm{C}$. After BM Purple staining, the embryos were washed thoroughly in $1 \times$ PBS or postfixed in $4 \%$ paraformaldehyde to stop the staining reaction and stored in $1 \times$ PBS/sodium azide $(0.02 \%)$ at $4^{\circ} \mathrm{C}$. After INT RED staining, the embryos were


PBTw or $4 \%$ paraformaldehyde at $4^{\circ} \mathrm{C}$.

For two-probe/two-color in situ hybridizations, probe synthesis and purification were done as described earlier. The prehybridization, hybridization, washing, and BM Purple staining for the first probe (the DIG-labeled RNA) were also performed as described earlier. Then, we followed the procedure of Liang et al. (9) for post-fixing and INT RED/BCIP detection of the second probe (the fluoroscein- or DNP-labeled probe). Briefly, the first staining reaction was stopped by post-fixing the em bryos in $4 \%$ paraformaldehyde/1× PBS overnight at $4{ }^{\circ} \mathrm{C}$ and then incubating them in $1 \times$ MABTw, $\mathrm{pH} 7.5$, twice for $20 \mathrm{~min}$ at room temperature; $1 \times$ MABTw + $10 \mathrm{mM}$ EDTA for $10 \mathrm{~min}$ at $70^{\circ} \mathrm{C}$; and then $100 \% \mathrm{MeOH}$ for $10 \mathrm{~min}$ at $25^{\circ} \mathrm{C}$. Embryos were then rehydrated through a graded $\mathrm{MeOH} / \mathrm{MABTw}$ series and washed four times for $10 \mathrm{~min}$ at $25^{\circ} \mathrm{C}$ in $1 \times$ MABTw. Embryos were blocked in Blocking Solution B for 1-4 $\mathrm{h}$ at $25^{\circ} \mathrm{C}$. Pre-adsorbed anti-DNP or anti-fluorescein AP-conjugated antibodies were added at a 1:500-1:5000 dilution in Blocking Solution B and incubated with embryos overnight at $4{ }^{\circ} \mathrm{C}$ with mild shaking. Antibody was removed by multiple washes with MABTw with mild shaking, followed by three rinses with staining buffer $(0.1$ M Tris- $\mathrm{HCl}, \mathrm{pH} 9.5,0.1 \mathrm{M} \mathrm{NaCl}, 50$ $\mathrm{mM} \mathrm{MgCl}_{2}, 0.1 \%$ Tween 20, $5 \mathrm{mM}$ Levamisol) for $5 \mathrm{~min}$ at room temperature. The INT RED stain was developed and stopped as described earlier.

\section{REFERENCES}

1.Baccard-Longere, M., B. Alpha-Bazin, C. Chypre, S. Sauvaigo, R. Teoule, P. Bernard, and J.M. Seigneurin. 1994. Fast, solid support detection of human papillomavirus in vitro am plified DNA using a DNP-anti DNP monoclonal antibody couple. J. Virol. Methods 46:29-38.

2.Bisgrove, B.W., J.J. Essner, and H.J. Yost. 1999. Regulation of midline development by antagonism of lefty and nodal signaling. Development 126:3253-3262.

3.Cubie, H.A., L.A. Duncan, L.A. Marshall, and N.M. Smith. 1997. Detection of respiratory syncytial virus nucleic acid in archival postmortem tissue from infants. Pediatr. Pathol. Lab. Med. 17:927-38.

4.Daniel, S.G., M.E. Westling, M.S. Moss, and B.D. Kanagy. 1998. FastTag TM nucleic acid labeling system: a versatile method for incorporating haptens, fluorochromes, and affinity ligands into DNA, RNA, and Oligonucleotides. BioTechniques 24:484-489.

5.Essner, J.J., W.W. Branford, J. Zhang, and H.J. Yost. 2000. Mesendoderm and left-right brain, heart and gut development are differentially regulated by pitx2 isoforms. Development 127:1081-1093.

6.Griffin, K.J., S.L. Amacher, C.B. Kimmel, and D. Kimelman. 1998. Molecular identification of spadetail: regulation of zebrafish trunk and tail mesoderm formation by T-box genes. Development 125:3379-3388.

7.Harper, S.J., E. Bailey, C.M. McKeen, A.S. Stewart, J.H. Pringle, J. Feehally, T. Brown, and R. Bright. 1997. A comparative study of digoxigenin, 2,4-dinitrophenyl, and alkaline phosphatase deoxyoligonucleotide labels in non-radioisotopic in situ hybridisation. J. Clin. Pathol. 5:686-690,

8.Lehtovaara, P., M. Uusi-Oukari, P. Buchert, M. Laaksonen, M. Bengtstrom, and M. Ranki. 1993. Quantitative PCR for hepatitis B virus with colorimetric detection. PCR Methods Appl. 3:169-175.

9.Liang, J.O., A. Etheridge, L. Hantsoo, A.L. Rubinstein, S.J. Nowak, J. Izpisúa Belmonte, and M.E. Halpern. 2000. Asymmetric nodal signaling in the zebrafish diencephalon positions the pineal organ. Development
127:5101-5112.

10. Rebagliati, M., R. Toyama, P. Haffter, and I.B. Dawid. 1998. Cyclops encodes a nodal-related factor involved in midline signaling. Proc. Natl. Acad. Sci. USA 95:9932-9937.

11.Sagerström, C.G., Y. Grinblat, and H. Sive. 1996. Anteroposterior patterning in the zebrafish, Danio rerio: an explant assay reveals inductive and suppressive cell interactions. Development 122:1873-1883.

12.Schulte-Merker, S., F.J.M. van Eeden, M.E. Halpern, C.B. Kimmel, and C. Nüsslein-Volhard. 1994. no tail (ntl) is the zebrafish homologue of the mouse T(Brachyury) gene. Development 120:1009-1015.

13.Tsang, M., R. Kim, M.P. de Caestecker, T. Kudoh, A.B. Roberts, and I.B. Dawid. 2000. Zebrafish nma is involved in TGF $\beta$ family signaling. Genesis 28:47-57.

We thank $R$. Hartley for comments on the manuscript. The authors have no financial interests in and no remunerative arrangements with any of the companies mentioned in this paper. This work was supported by a Pilot Award from the University of Iowa Diabetes and Endocrinology Research Center, National Institutes of Health grant no. DK25295, and Biosciences Pilot grant no. from the State of Iowa. Address correspondence to Dr. Michael Rebagliati, Room 1-570BSB, 51 Newton Road, Department of Anatomy and Cell Biology, College of Medicine, University of Iowa, Iowa City, IA 52242, USA. e-mail:michael-rebagliati@uiowa.edu.

Received 17 May 2001; accepted 16 November 2001.

\section{Sarah Long and Michael Rebagliati} University of Iowa Iowa City, IA, USA

For reprints of this or
any other article, contact
Reprints@BioTechniques.com

